\title{
Ensuring usability of future smart energy control room systems
}

\author{
Tilo Mentler*, Tim Rasim, Marcel Müßiggang and Michael Herczeg \\ From The 7th DACH+ Conference on Energy Informatics \\ Oldenburg, Germany. 11-12 October 2018
}

\author{
${ }^{*}$ Correspondence: \\ mentler@imis.uni-luebeck.de \\ Institute for Multimedia and \\ Interactive Systems (IMIS), \\ University of Luebeck, Ratzeburger \\ Allee 160, Bldg. 64, D-23562 \\ Luebeck, Germany
}

\begin{abstract}
Energy providers face several technical and societal challenges with respect to renewable energies and smart energy systems. As central management units of energy supply systems, control rooms and their operators are especially affected by those changes. While reliability and safety of software systems for managing electric power grids is of utmost importance, their usability has to be ensured as well in order to allow for safe and efficient operations. Previous work has failed to address issues of work reengineering and user interface design for future smart energy control rooms due to insufficient collaboration of human-computer interaction researchers, energy informatics researchers and energy sector stakeholders. This paper describes challenges and approaches for ensuring usability of future smart energy control room systems. It is based on a human-centered design process within an interdisciplinary research project bringing together the aforementioned groups of experts. Results were derived from systematic literature review, workshops and surveys with control room operators as well as contextual inquiries in three control rooms. They concern both the process of realising software systems for managing electric power grids and applications characteristics with respect to user interface design. It is concluded that open and modular software systems require consistent user interfaces based on a style guide. Furthermore, software and usability engineering processes of energy control systems have to be aligned in order to ensure usability, safety and security.
\end{abstract}

Keywords: Usability, Control room, Smart energy systems, Big data, Low-voltage management

\section{Introduction}

Control rooms, as "location[s] designed for an entity to be in control of a process" (Hollnagel and Woods 2005) in general, have changed considerably with respect to available information and communication technologies, human-machine task allocation, levels of automation and user interface design in many fields of application since the 1950s - among them the energy sector (see Fig. 1, cf. (Herczeg 2014)).

Long-term societal and technical challenges (e.g. reducing greenhouse gas emissions, raising the share of renewable energies, implementing smart energy systems, cf. (Neureiter et al. 2016; Santini and Tiefenbeck 2018)) will have an impact on the design of future "smart control room[s]" (Wang and Qi 2012). While technical reliability and safety

(c) The Author(s). 2018 Open Access This article is distributed under the terms of the Creative Commons Attribution 4.0 International License (http://creativecommons.org/licenses/by/4.0/), which permits unrestricted use, distribution, and reproduction in any medium, provided you give appropriate credit to the original author(s) and the source, provide a link to the Creative Commons license, and indicate if changes were made. 


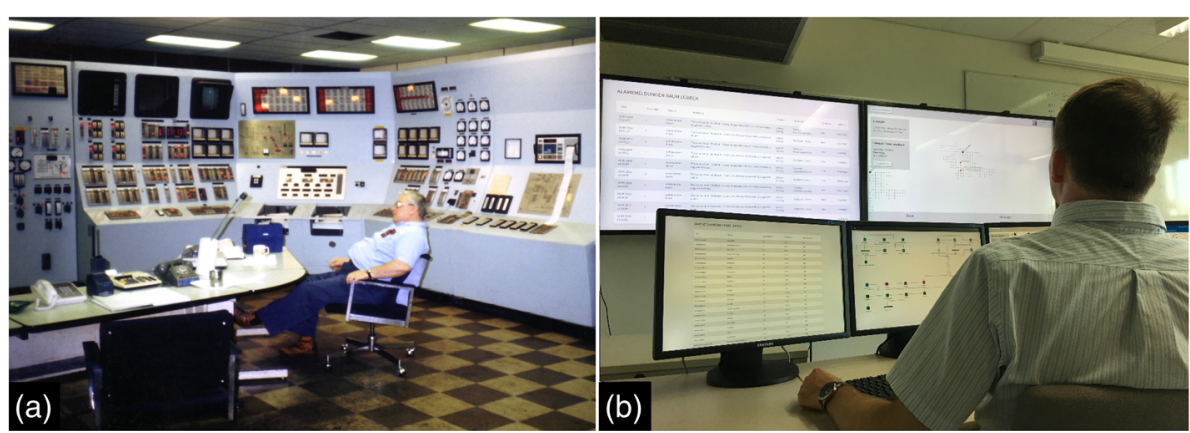

Fig. 1 (a) Control room with analogue elements (photo: published here with permission of Achim Hering) (b) Replica of a state of the art workstation in energy control rooms integrating public wall-mounted displays and several private screens (photo: copyright IMIS)

of software systems for monitoring and managing smart energy systems is of utmost importance, their usability, as "extent to which a system, product or service can be used by specified users to achieve specified goals with effectiveness, efficiency and satisfaction in a specified context of use" (ISO 9241-11, 2018), has to be considered in order to ensure or restore safe and efficient operations.

Energy control room operators' working conditions are characterised by high cognitive demands both in daily routine and under extraordinary circumstances even now (Herczeg 2014; Schwarz 2015). Shift operations and several hours of sitting constitute physical load in the long term. Future smart energy control room systems must be designed in due consideration of these circumstances.

"Historically, there has been an overreliance on the next generation of user-interface media to address issues like usability" (Butler 1996). In this regard, two research questions will be addressed in the following sections:

1 How should future smart energy control room systems be designed with respect to usability issues?

2 How should user interface design of smart energy control systems be guided?

Firstly, background and related work of human-centered design, usability of energy control rooms, the interdisciplinary research project NetzDatenStrom and the openKonsequenz $(\mathrm{oK})$ consortium are explained. After describing human-centered design methods applied, (e.g. contextual inquiries, affinity diagramming), results are discussed. Conclusions will be drawn and reflected upon in the last section.

\section{Background and Related Work}

In the following sections, basic principles and process models of human-centered design are described. Afterwards, related work and studies about usability of (energy) control rooms are summarised. Finally, the interdisciplinary research project NetzDatenStrom and oK consortium framing this work are introduced.

\section{Basic Principles of Human-Centered Design}

Human-centered design is "an approach to interactive systems development that aims to make systems usable and useful by focusing on the users, their needs and requirements, and by applying human factors/ergonomics, and usability knowledge and techniques" 
(ISO 9241-210, (2010)). Figure 2 shows the basic analyse-design-build-evaluate-lifecycle. Iterations are driven by insights from formative and summative evaluations with respect to users and their tasks.

The process model of ISO 9241-210:2010 has been elaborated in more sophisticated ones like Contextual Design (Beyer and Holtzblatt 1998), Scenario-Based Design (Rosson et al. 2002) or the Usability Engineering Lifecycle (Mayhew 1999). All of them "embrace but are certainly not limited to user interface and interaction design" (Mentler et al. 2017). Reengineering work "to more effectively support business goals" (Mayhew 1999) is a crucial part of human-centered design because tasks and tools coevolve (Carroll et al. 1991). Therefore, a proper understanding of a context of use and implications with respect to workflows and organisational structures is necessary.

Usability, as defined in the previous section, has been the major criteria for assessing human-centered design efforts. In addition, user experience (UX), as a "person's perceptions and responses resulting from the use and/or anticipated use of a product, system or service" (ISO 9241-210, (2010)), has become an important issue for system designers even in safety-critical application domains (Mentler 2018).

\section{Usability and User Experience of Control Rooms Systems}

Several studies addressing usability and user experience have been devoted to control rooms in different fields of applications. For example:

- Savioja et al. (2012) conducted a study with 70 operators in two power plants consisting of an orientation interview, multiple analyses of observed behaviour in a simulated crisis and a systems usability questionnaire. They state: "The learnability of the control room systems was considered in both plants not to be on an optimal level. [...] The operators made statements that in fact it is confusing to have different

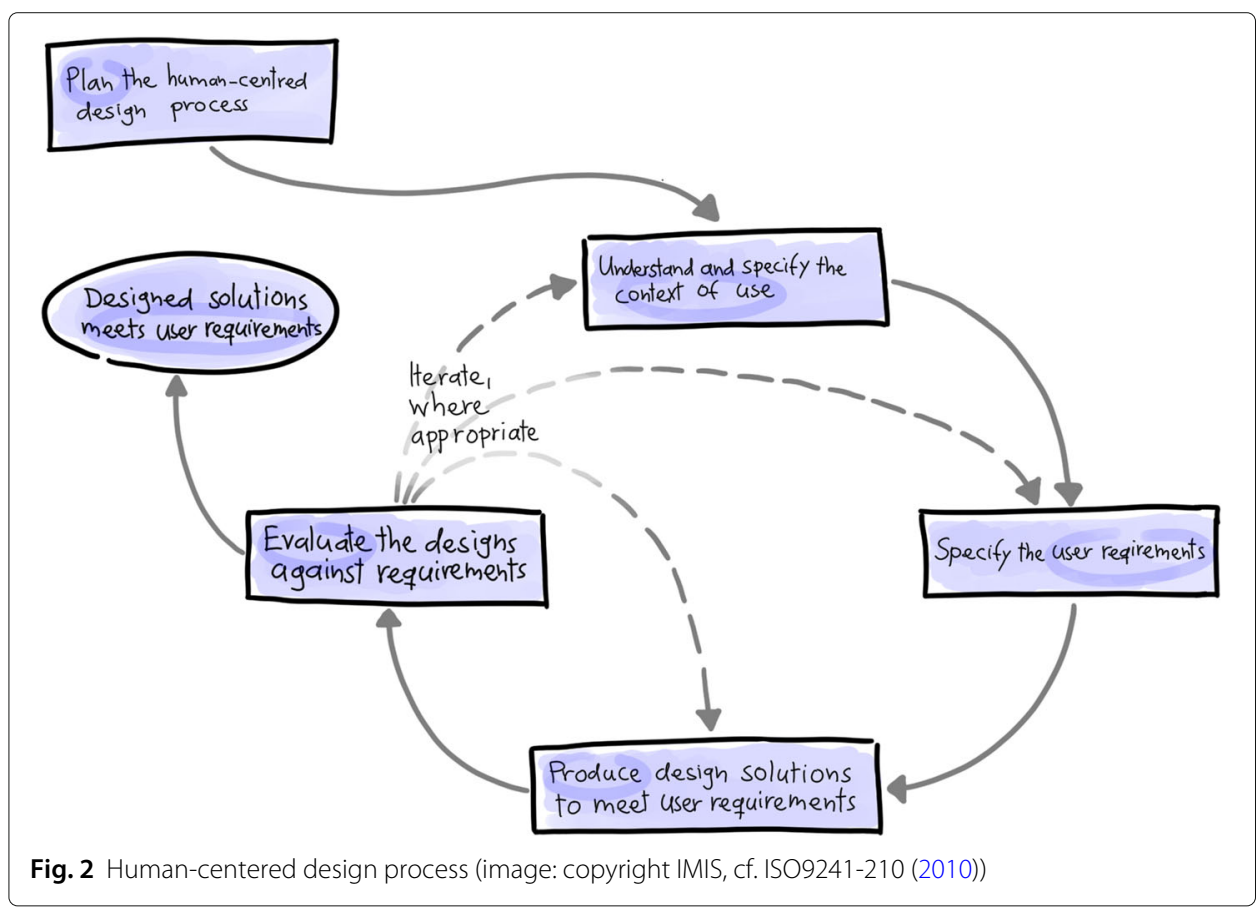


information presentation principles and notations within the systems of the same control room."

- Savioja et al. (2014) conducted multiple studies to evaluate the usability of control rooms in nuclear power plants. Four of the studies where done in simulators and one in active control rooms. The number of participating operators was between 9 and 42 (39 in the real control room study). They summarised their experience with the alarms management as the following: "Most problematic communicative features, according to the questionnaire data, concerned the interpretation of the audio information in the control room, [...]"

- Domova et al. (2017) conducted contextual interviews with two to three operators per control room at an undisclosed number of industrial facilities, providing an apt description of the operator's daily work: "According to the operators, a typical work shift consists of monitoring control processes they are responsible for, attending to alarms which indicate problems, diagnosing and troubleshooting the encountered problems."

- Bockelmann et al. (2012) developed a checklist and used it to study 27 workplaces in 24 control rooms. In Summary, "Furthermore, new trends in the design of control rooms needs to be taken into account, such as the increase of usability and accessibility aspects and their proper application in this scope."

- Ivergard and Hunt (2009) summarise their experiences in the field of control room design: "As most of these control rooms are used for continuous operation, ergonomic aspects are also very important. This includes the design and usability of the lighting and furniture (consoles, chairs, and work surfaces), as well as the technological aspects (with a 24/7 capability)."

While all the mentioned studies agree that usability issues must be solved in control rooms, future challenges raised by smart energy systems (e.g. big data applications) and design implications have not been considered.

\section{Project NetzDatenStrom and OpenKONSEQUENZ consortium}

The interdisciplinary research project NetzDatenStrom framing the human-centered design activities described in this contribution is funded by the German Federal Ministry of Economic Affairs and Energy within the 6th energy research program ${ }^{1}$. Humancomputer interaction researchers, energy informatics researchers and energy sector stakeholders collaborate on integrating Big Data applications for low-voltage energy grids into existing energy control room systems in a standard-compliant way. A particular focus is on the usability of user interfaces in control room systems for operators and service personnel.

One of the NetzDatenStrom project partners is the oK consortium ${ }^{2}$ comprising distribution system operators, software vendors, service providers and researchers. They collaborate to improve energy and gas grid control rooms. The goal of oK consortium is to drive the development of grid control systems towards open source, thus reducing maintenance costs of their systems landscape by reducing system complexity and vendor dependency as well as increasing software quality (e.g. usability) and software development efficiency. To further this goal, oK members develop open source modules that are meant to be interoperable. As a consortium of multiple distribution system operators they define framework conditions to ensure modules developed to their standards 
will be compatible. These conditions include the oK Multilayer Architecture (see Fig. 3) providing a general structure to ensure reusability, modularisation, and extendibility.

Considering the oK multilayer architecture, previous works within the scope of oK dealt mostly with the technical aspects of backend. The investigations carried out in the context of this paper and project should help to ensure a consistent and usable design across all modules developed at the user modules layer.

\section{Methods}

Apart from workshops and regular meeting with NetzDatenStrom project partners, specific measures were implemented in order to understand and specify the context of use as well as derive recommendations for ensuring usability of future smart energy control room systems (see Fig. 4).

A systematic literature review was conducted in the periods 18.05.2017-08.06.2017 and 12.03.2018 - 07.05.2018 with the aid of literature search engines and digital libraries (ACM Digital Library, IEEE Xplore Digital Library, ScienceDirect, Digital Library of the German Informatics Society) in order to gain a proper understanding of current and future challenes for energy control systems, using terms related to the fields of human computer interaction, safety critical systems, and big data. Apart from the previously mentioned studies, results included best practices (e.g. (Crampin 2017)), guidelines (e.g. (EPRI and U S Department of Energy 2004)), standards (e.g. ISO 11064-4, (2013)) and technical reports (e.g. (Bundesanstalt für Arbeitsschutz und Arbeitsmedizin (BAuA) 2014)).

The ISONORM 9241-110-S questionnaire ${ }^{3}$ (cf. (Pataki et al. 2006)) operationalises the following seven dialogue principles for interactive systems as described in ISO 9241-110:2006:

- Suitability for the task: Does the interactive system support task completion by providing functions and dialogues based on task- and user-specific characteristics rather than technological issues?

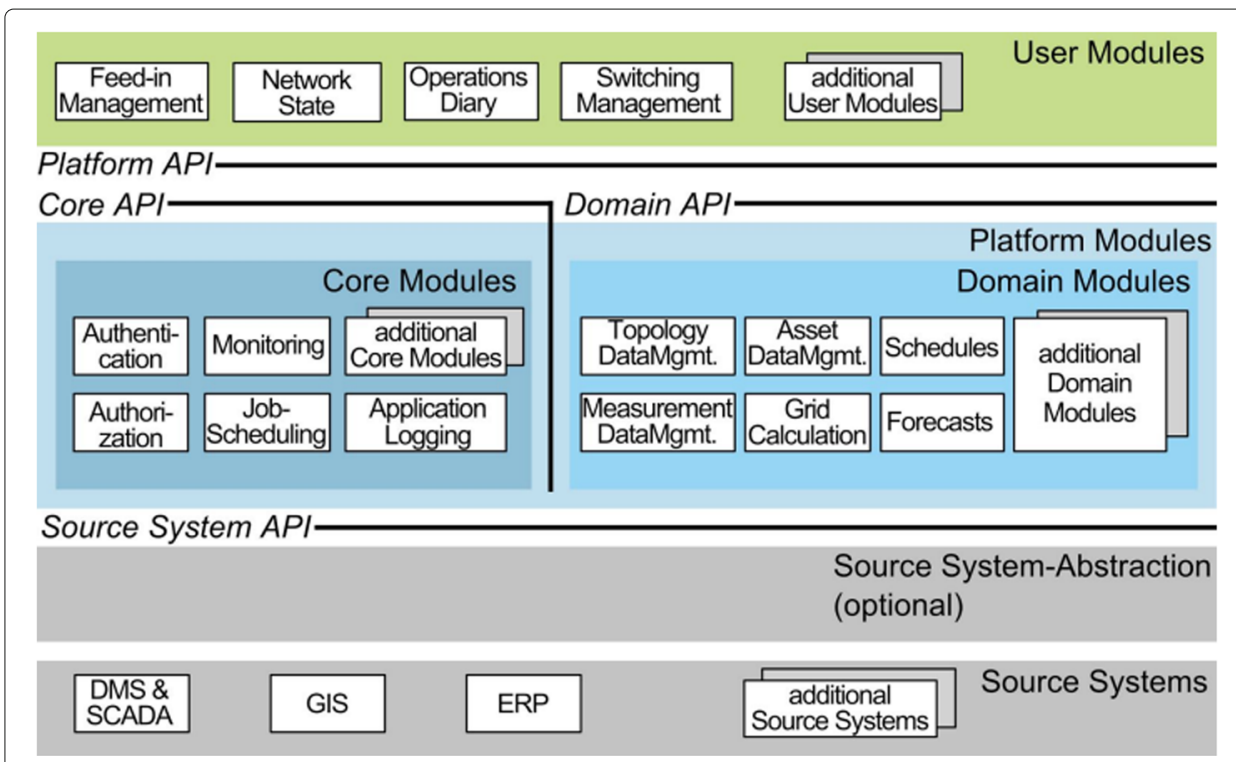

Fig. 3 oK Multilayer Architecture (Goering et al. 2017) (image: published here with permission of Matthias Rohr) 


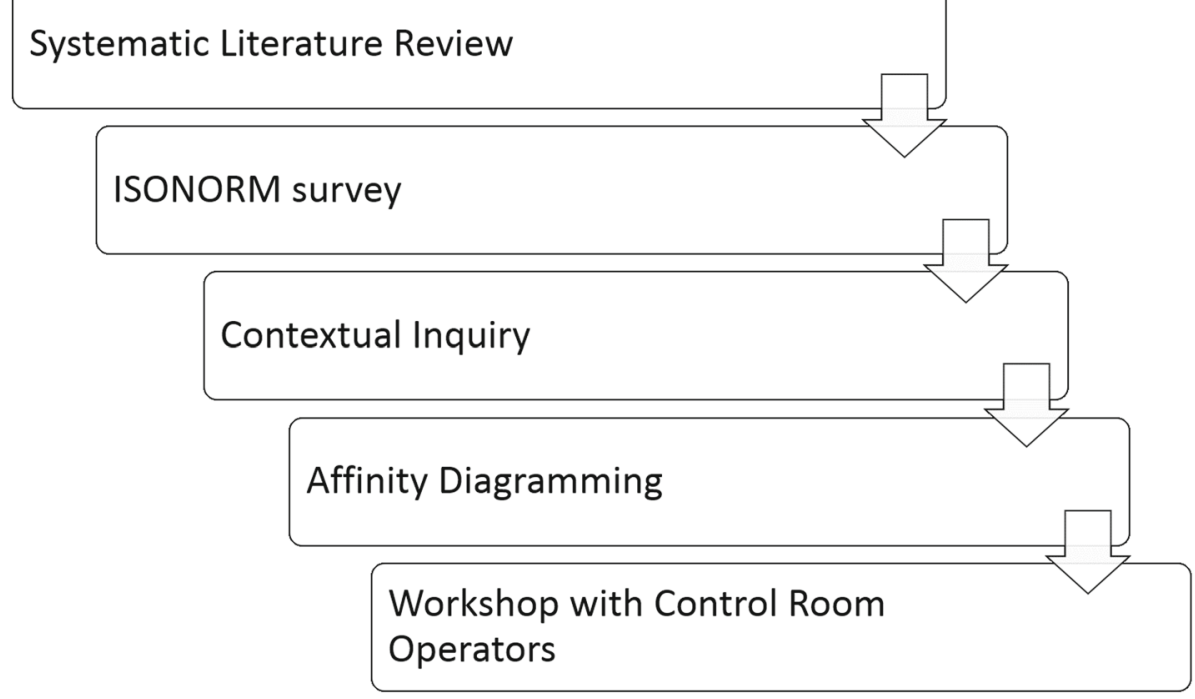

Fig. 4 Human-centered design workflow as part of context of use analysis (image: copyright IMIS)

- Self-descriptiveness: Does the user know at any time which options are available and how they could be accomplished?

- Conformity with user expectations: Does the interactive system comply with users' concerns and approved conventions?

- Suitability for learning: Does the interactive system support and guide users in using it?

- Controllability: Is the user able to control paces and sequences of interaction processes?

- Error tolerance: Does the interactive system support error control, correction and management?

- Suitability for individualisation: Could the interactive system be customised to suit individual users?

There are 3 questions for each of these items offering a 7-point bi-polar Likert scale. Accompanied by some questions about professional experience and workplace layout, the ISONORM 9241-110-S questionnaire was made available online. Possible participants were addressed by NetzDatenStrom project partners and a newsletter to the oK community.

Contextual inquiry is a special form of interview in a kind of apprentice-master relationship to collect data with the aim of gaining reliable knowledge about tasks, work process and artefacts used. As part of the research project, three different energy control rooms were visited in each case by two researchers who took on the role of the interviewer. In order to identify possible deviations or differences in the interaction with the control room system, different shifts from early to night were visited. In addition the process of shift changeovers could be observed. In order to not influence the operator in his working processes, the use of video recordings was dispensed with and only observations were made. To ensure a uniform process of the interview, an observation questionnaire 
was designed in advance and used during the interview in all three control rooms. Furthermore, printed copies of the ISONORM-S questionnaire were distributed in order to allow operators to assess the usability of the energy control room systems used. During the observations, the interviewers made handwritten notes, so-called affinity notes, which were categorised, catalogued and associated later on.

Data obtained from the contextual inquiry is usually extensive and complex in its details. In order to be able to recognise structures and derive regularities from these data, affinity diagrams are created. With the help of affinity diagrams, the data can be displayed clearly and orderly.

Figure 5 shows the consolidated data of the three energy control room visits in the form of an affinity diagram. Here the essential points, which were written down as affinity notes, are collected and arranged according to their importance and to their similarity among each other. The affinity notes describe statements, problems, information and design ideas. These coherent sets of notes are then sorted into a previously undefined group. The diagrams were developed in a creative laboratory with three researchers, who also visited the energy control rooms, and a student assistant. Additionally, the affinity diagram was digitalised for further use of the consolidated data.

Finally, a half-day workshop with 6 operators of a specific control room was conducted by one researcher. After a short introduction of participants, challenges and approaches to smart energy systems and low-voltage management strategies were discussed with respect to the insights gained from the previous measures.

\section{Results}

In the following sections, insights gained from the previously described measures are presented and discussed. After summarising results of the ISONORM questionnaire, questions of smart energy control room design are discussed.

\section{ISONORM 9241-110-S questionnaire}

Fourty energy grid control operators participated in the inquiry about the usability in current control rooms between 14.03.2017 and 17.08.2017. 80\% of the respondents worked in

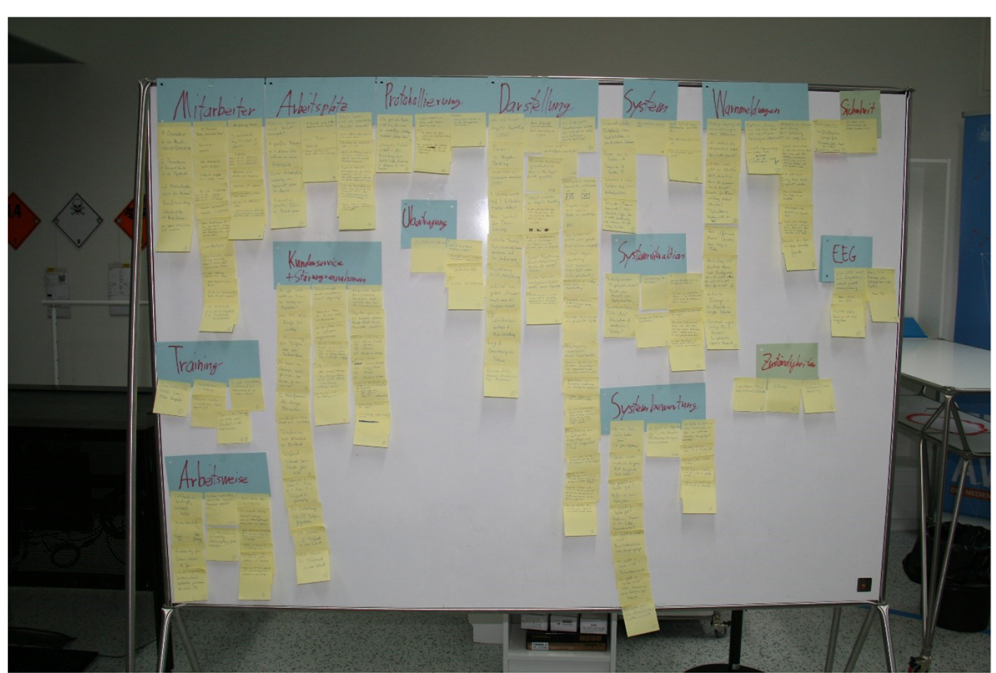

Fig. 5 Affinity diagramming after contextual inquiries in 3 control rooms (photo: copyright IMIS) 
this position for more than five years. In order to gain an understanding of user interfaces in energy grid control rooms, participants were asked which input devices and how many monitors are used at their workplaces (see Table 1). The answers reveal that the classic paradigm "Windows, Icons, Menus, Pointer" (WIMP) is still state of the art in energy control rooms. However, the share of other interaction paradigms (e.g. touch, voice) will increase most likely. The varying numbers of displays available to different control room operators is noteworthy.

Within the NetzDatenStrom project, two basic use cases with respect to smart energy systems low-voltage management have been identified (failure management and plausibility checks). In this regard, operators were asked how often corresponding tasks (e.g. receiving error reports from customers) are carried out currently (see Table 2).

Results of ISONORM 9241-110-S questionnaire are summarised in Table 3. Attention should be paid to the fact that they abstract from specific companies and products in order to gain a general impression of state-of-the-art control room design.

Results show that there is room for improvement, especially with respect to suitability for learning, suitability for individualisation, self-descriptiveness and error tolerance. Considering both increasing complexity of technical infrastructure (e.g. big data applications, decentralised and distributed grids) and control room operators' future workload, improving upon on these factors and usability in general is of utmost importance.

\section{Same, same but different - State of the art of energy control rooms}

The previously described human-centered design activities revealed major differences in the design of current energy control rooms with respect to number and layout of workstations, human and technical resources as well as operators' responsibilities.

For example, Fig. 6 shows the basic layout of energy control rooms visited in the course of this study. Private workspaces (green) intended to be used by one operator only and shared workspaces (blue) intended to be used by several operators.

In control room 1, operators always face a wall and people entering through one of the doors cannot immediately see their displays, other operators need to actively turn around to do so. In control room 2, the supervising operator sits in a separated room; the other operators sit together facing the walls. In their backs is an additional partition wall, making it hard to spontaneously watch over their shoulders. In control room 3 , an entrance area is separated from the main control room. There all workstations are setup in front facing rows, enabling the operators sitting in the back to view the screens of those in front of them. Visitors walking in through the main door will immediately be able to view their screens content. Bockelmann et al. (2012) argue that a positioning such as this creates an atmosphere of being observed and can impacts the operator's wellbeing.

Table 1 Questionnaire answers regarding physical user interfaces

\begin{tabular}{|c|c|c|c|c|c|c|}
\hline Item & Mouse & Keyboard & Pen \& paper & Touch device & Digital pen & Voice \\
\hline $\begin{array}{l}\text { Which Input devices do } \\
\text { you use? (percentage of } \\
\text { operators agree) }\end{array}$ & $100,00 \%$ & $97,50 \%$ & $27,50 \%$ & $5 \%$ & $0 \%$ & $0 \%$ \\
\hline Item & & & & Minimum & Maximum & Average \\
\hline $\begin{array}{l}\text { How many displays are } \\
\text { available to solve your } \\
\text { tasks? (Answer with one } \\
\text { number) }\end{array}$ & & & & 2 & 13 & 6.13 \\
\hline
\end{tabular}


Table 2 Questionnaire answers regarding the regularity of specified tasks

\begin{tabular}{|c|c|c|c|c|c|}
\hline Task & Daily & Weekly & Monthly & $\begin{array}{l}\text { Less than once a } \\
\text { month }\end{array}$ & Never \\
\hline $\begin{array}{l}\text { Receiving error reports from } \\
\text { customers }\end{array}$ & $47.5 \%$ & $10 \%$ & $12.5 \%$ & $12.5 \%$ & $17.5 \%$ \\
\hline $\begin{array}{l}\text { Forwarding error reports for } \\
\text { localisation }\end{array}$ & $65 \%$ & $10 \%$ & $10 \%$ & $2.5 \%$ & $12.5 \%$ \\
\hline Localising reported errors & $55 \%$ & $22.5 \%$ & $10 \%$ & $5 \%$ & $7.5 \%$ \\
\hline $\begin{array}{l}\text { Forwarding localised errors to a } \\
\text { technician }\end{array}$ & $65 \%$ & $12.5 \%$ & $7.5 \%$ & $7.5 \%$ & $7.5 \%$ \\
\hline Solving localised errors on site & $2.5 \%$ & $2.5 \%$ & $0 \%$ & $5 \%$ & $82.5 \%$ \\
\hline $\begin{array}{l}\text { Checking data plausibility with } \\
\text { weather information }\end{array}$ & $35 \%$ & $15 \%$ & $7.5 \%$ & $12.5 \%$ & $30 \%$ \\
\hline
\end{tabular}

Control room 1 included four workstations and a public display space, one of the workstations was used to control a water grid, two to control an energy grid and the fourth as a backup. Control room 2 was the only one that solely consisted of workstations for energy grids of which five were actively used and two remained as backups. In control room 3 four stations were reserved for energy grid controls with one additional backup station in the entrance area. On two further stations grids for gas and central heating were managed. Figure 7 shows private workspaces in different control rooms with respect to utilisation of available displays. Those marked in green are connected to the control system and show information of the controlled energy grids. They were set to different views (alarm view, detail list, information graphs, detailed logical views or overall logical view) to the preferences of the acting operator. Displays marked in orange are connected to standard hardware running various office applications (Outlook, Word, Excel) as well as third party applications like geographic information systems (GIS).

Table 3 ISONORM 9241/110-S evaluation ( $n=40$, range from 1 (very bad) to 7 (very good))

\begin{tabular}{|c|c|c|c|c|c|}
\hline Factor & Aspect & Mean & SD & Median & Sum \\
\hline \multirow[t]{3}{*}{ Suitability for tasks } & Integrity & 5.1 & 1.19 & 6.0 & 16.3 \\
\hline & Streamlining & 5.5 & 1.18 & 6.0 & \\
\hline & Fitting & 5.7 & 0.85 & 6.0 & \\
\hline \multirow[t]{3}{*}{ Self-descriptiveness } & Information content & 5.3 & 1.14 & 6.0 & 14 \\
\hline & Potential support & 4.5 & 1.41 & 5.0 & \\
\hline & Automatic support & 4.2 & 1.66 & 4.0 & \\
\hline \multirow[t]{3}{*}{ Conformity with user expectations } & Layout conformity & 5.7 & 1.21 & 6.0 & 16.8 \\
\hline & Transparency & 5.3 & 1.37 & 5.5 & \\
\hline & Operation conformity & 5.8 & 1.12 & 6.0 & \\
\hline \multirow[t]{3}{*}{ Suitability for learning } & Learnability & 4.0 & 1.47 & 4.0 & 11.7 \\
\hline & Visibility & 4.1 & 1.53 & 4.0 & \\
\hline & Deductibility & 3.7 & 1.52 & 4.0 & \\
\hline \multirow[t]{3}{*}{ Controllability } & Flexibility & 5.3 & 1.33 & 5.5 & 16.6 \\
\hline & Changeability & 5.7 & 1.23 & 6.0 & \\
\hline & Continuity & 5.6 & 1.53 & 6.0 & \\
\hline \multirow[t]{3}{*}{ Error tolerance } & Comprehensibility & 5.0 & 1.30 & 5.0 & 14.2 \\
\hline & Correct ability & 5.0 & 1.12 & 5.0 & \\
\hline & Correction support & 4.2 & 1.51 & 4.0 & \\
\hline \multirow[t]{3}{*}{ Suitability for individualisation } & Extensibility & 3.8 & 1.85 & 4.0 & 13 \\
\hline & Personalisation & 4.6 & 1.91 & 5.0 & \\
\hline & Flexibility & 4.6 & 1.81 & 5.0 & \\
\hline
\end{tabular}




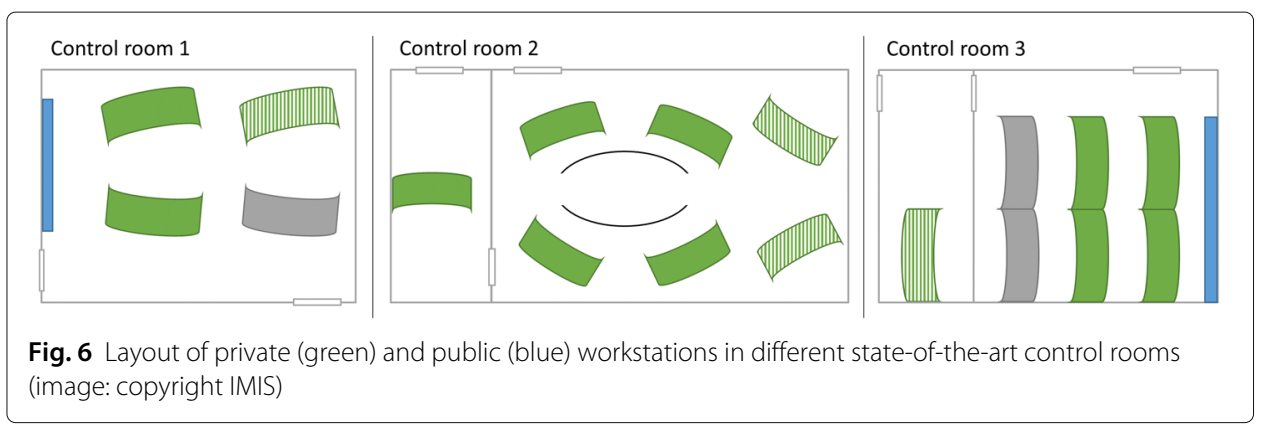

One focus point of the conducted study is the difference in the work environment between day and night shifts. It can be noted, that all control rooms used similar shift models where the operators are typically part in one of four shifts:

- early shifts starting in the early morning and ending mid-day,

- late shifts starting in the mid-day and ending in the late evening,

- night shifts from the late evening until early morning,

- and day shifts at regular business hours.

This means the operator of the early, late or night shift is present at all times to resolve emergencies and at business hours additional capacities are available for routine tasks. Control room 1 uses one operator for each shift, control room 2 uses two operators for its rotating shifts and three for its day shift, and control room 3 has one operator in the rotating shifts and two in the day shift. Operators sometimes have trainees with them, this was the case in one shift at control room 3.

In summary, it can be stated that open and modular system architectures for future energy control room systems - as suggested by oK consortium - are essential not only to decrease dependences on few manufacturers and to enable shorter update frequencies (Goering et al. 2016) but to increase suitability for individualisation and reflect major differences in the design of energy control rooms. However, well-defined workflows (see the following section) and consistent user interfaces (see the section after next) are necessary to ensure usability of smart energy control room systems.

\section{To be or not to be - Low-voltage management and future energy control rooms}

In the context of smart energy systems, the question arises whether and to which degree control room operators will be involved in controlling and managing low-voltage energy grids. Our research revealed a disparity of opinions:

- Some control room operators were sure that low-voltage management will not become part of their daily work. They think of specialised service centres or third-party suppliers.

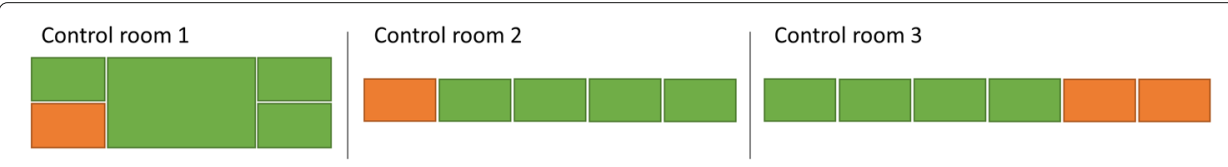

Fig. 7 Utilisation of displays at private workspaces (green = controlling various aspects of energy grids, orange $=$ third-party applications (e.g. office applications)) (image: copyright IMIS) 
- Other control room operators were sure that low-voltage management will become part of their daily work.

In either case, responsibilities, tasks and workflows must be clarified before implementing further software modules in control room systems. As shown before, suitability for learning has to be improved for current applications and must not be complicated by introducing more functionality not reflecting work in practice.

Hierarchical task analysis ((Shepherd 1998); see Fig. 8) and flow models ((Beyer and Holtzblatt 1998); see Fig. 9) are two approaches to representing and refining tasks and workflows.

Currently, task analysis and workflow models are discussed with NetzDatenStrom project partners and stakeholders. Consolidated versions will serve as a basis for user interface design - combined with the domain-specific style guide described in the next section.

\section{Open, Modular... and consistent - Guiding the style of future energy control rooms}

Due to the expedited open and modular development of energy control rooms, modules from various vendors could be integrated into current and future system solutions. As a result, different forms of interaction and design could be introduced leading to an increasing cognitive strain on the already demanding work of the operator.

In order to ensure situation awareness and support decision-making processes in critical situations, a consistent and usable design of user interfaces is essential. To achieve this in the context of energy control rooms, a first draft of a style guide has already been developed by the oK consortium. Style guides are structured collections of guidelines and rules to enhance consistency and usability in the development of user interfaces (Baumert 1998; Preim and Dachselt 2015). Previous approaches of style guides, usually linearly structured text documents in printed or digital design, are no longer sufficient for the development of complex and highly dynamic systems. However, despite numerous identified problems and a history of systematic failure, this approach is still being pursued nowadays (Gale and

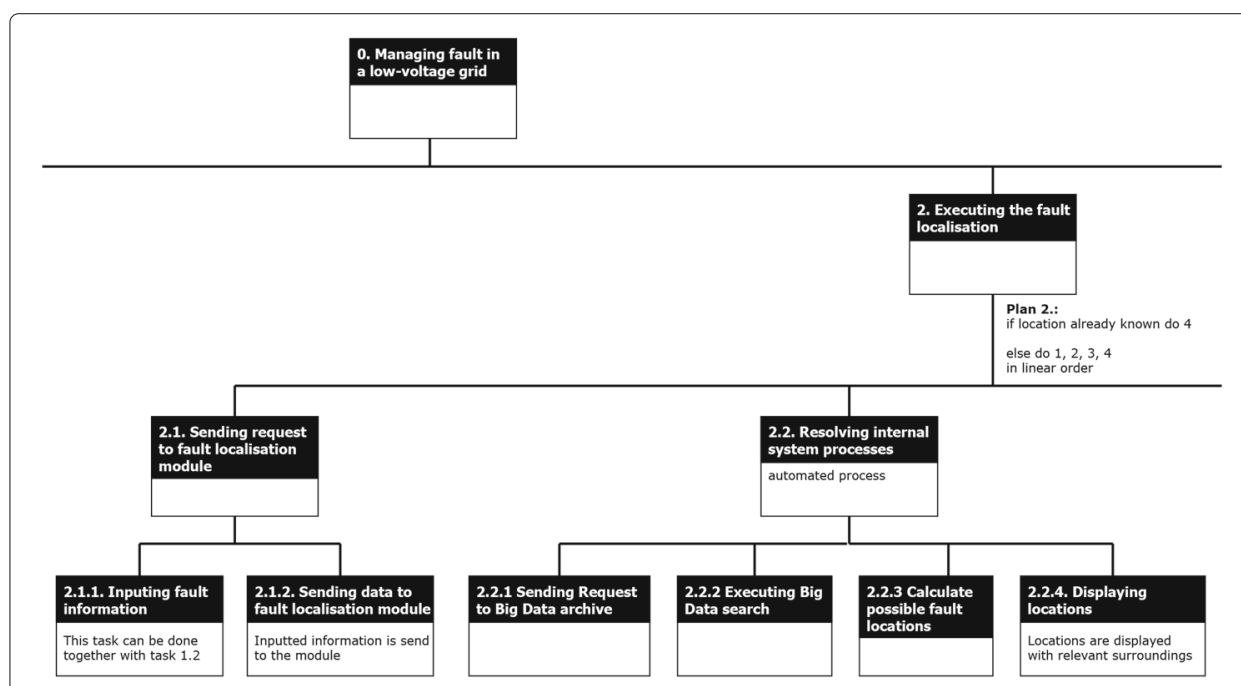

Fig. 8 Part of a hierarchical task analysis for managing low-voltage failures (modelled with the Usability Engineering Repository (UsER), cf. (Herczeg et al. 2013)) (image: copyright IMIS) 


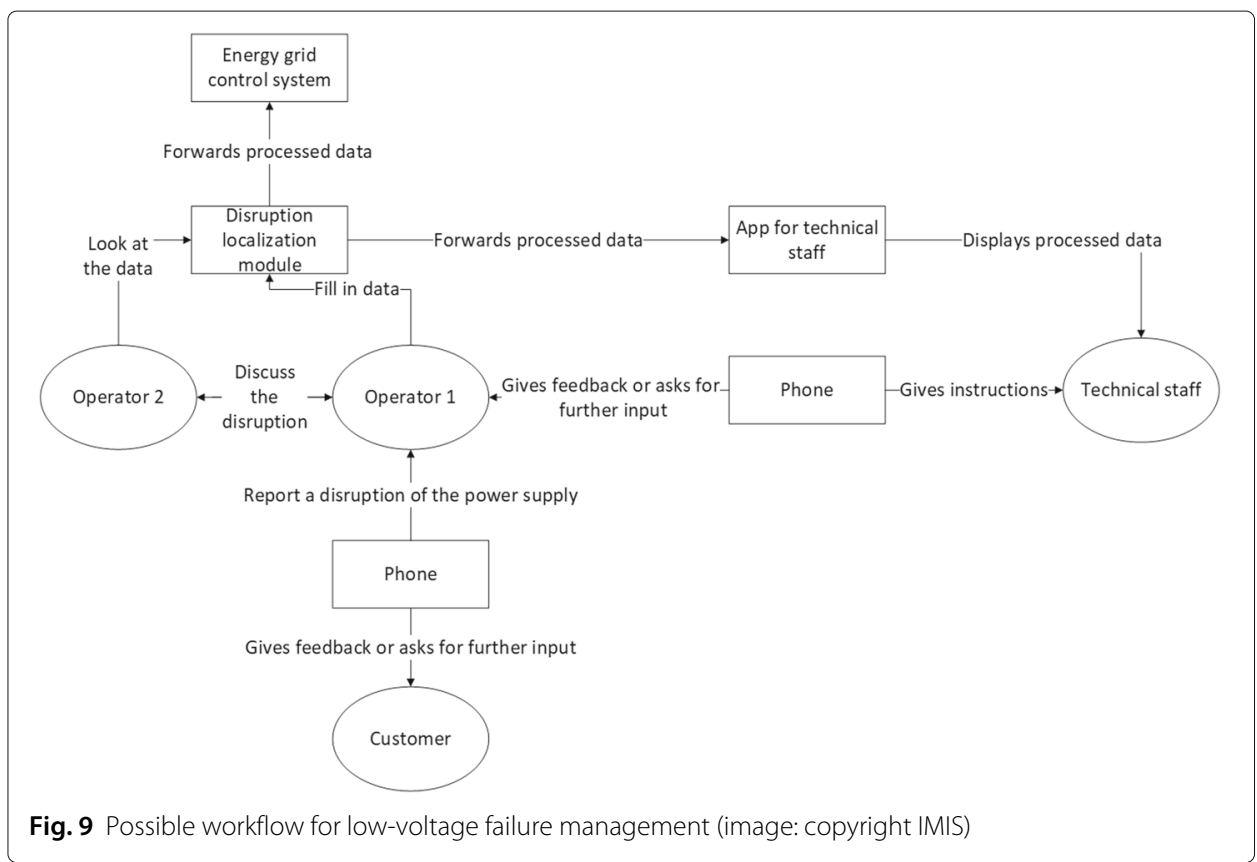

Stephen 1996; Reed et al. 1999). In order to keep up with the progressive technical development of the systems, the static approach of style guides has to evolve as well (Roenspieß and Herczeg 2013).

Part of the research project NetzDatenStrom is the development of a style guide for future user modules. To meet the outlined requirements, a "dynamic" and "living" style guide is being developed. It follows the strategy of enabling a more flexible navigation to individual elements through hypermedia structures, ongoing integration of user content and experience, and a simplified update and distribution of the style guide compared to previous approaches. One of the most important reasons for the failure of style guides is the insufficient or missing publication of updates (Wilson 2001). This is counteracted by a central administration that enables a fast updating and distribution process.

As shown in Fig. 10, users are offered the opportunity to test and experience individual elements of the style guide interactively, directly and live. The corresponding code elements can be copied or downloaded and used directly for further development. This makes the style guide an important and supportive tool for the development of new modules. The style guide serves as a collaboration platform between developers, users and other stakeholders. The implemented comment function allows to share experiences with respect individual design components, to point out missing elements and to get feedback in case of uncertainties. Different views and a corresponding rights management ensure that only authorised users are able to make changes on the actual version visible for everyone.

The structure of the style guides is based on the methodology of Atomic Design (Frost 2016). Design elements are classified into the categories atoms, molecules, organisms and templates according to their properties. Atoms are structurally the most basic components that cannot be broken down any further. These includes colours, fonts or buttons. Molecules describe groups of assembled atoms. For example the colour design of the atom "colour palette" can be combined with the structure of the button from the atom "button", 


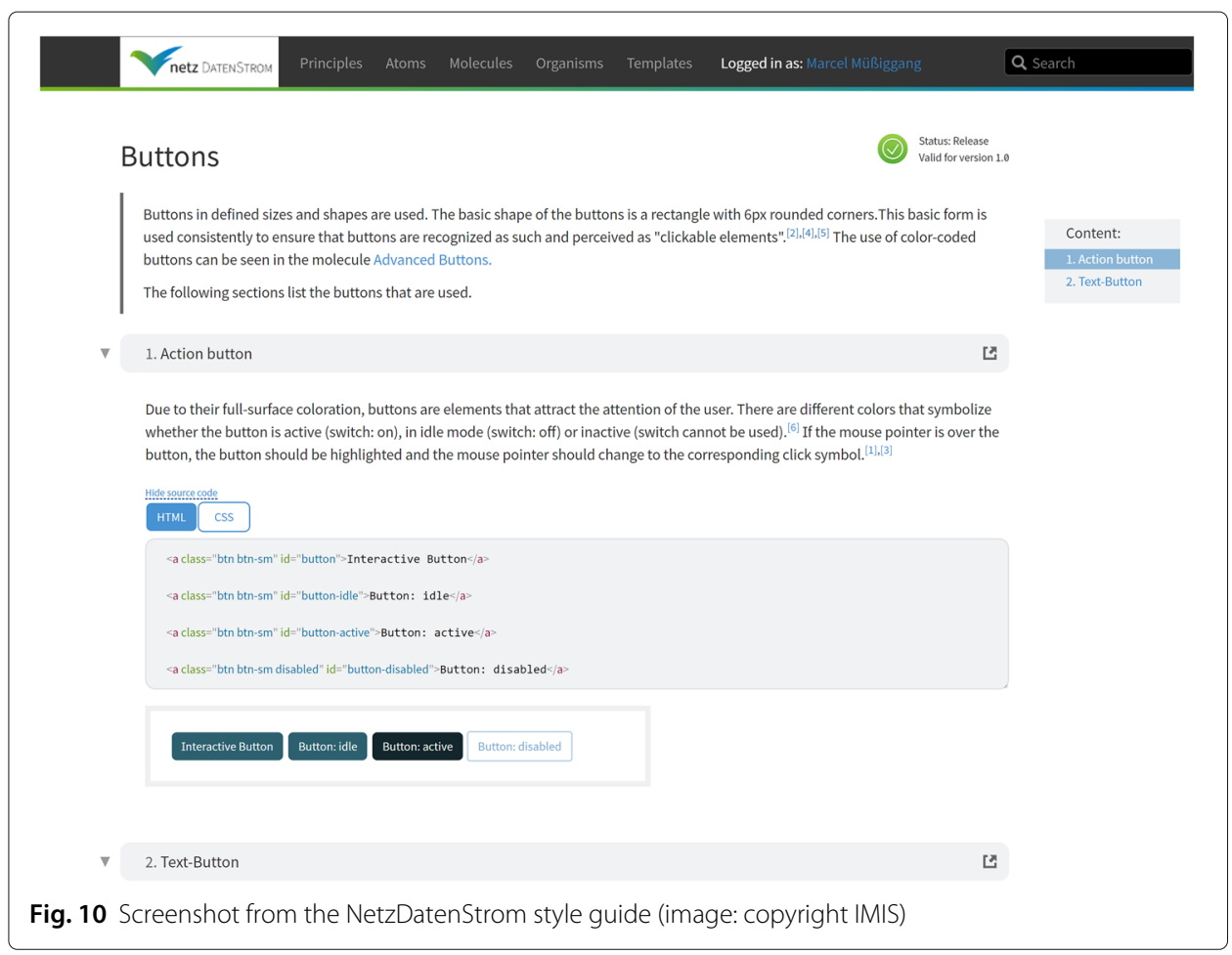

creating the molecule "advanced buttons". Organisms such as headers or stacked forms describe complex user interface components of atoms, molecules and other organisms.

Templates are used to insert components into a layout and describe the underlying content structure of the design. Human machine interfaces (HMI) in safety critical domains especially need to enable operators to act promptly and accurately in high risk situations. Rae (2007) describes multiple HMI patterns and guidelines which aim at keeping the operator in the loop without distracting him with unnecessary information. As Rae illustrates further, these guidelines can support non human factor experts in developing safe HMI solutions. For this reason a suitable style guide needs to offer comprehensible guidelines and design principles based on literature research and control room visits. These design principle have been added to the Atomic Design structure to provide a better context for the provided element descriptions. For example, a basic design principle for future energy control room systems is to observe the multiplecoded display of warnings and alarms. Both structure and content of the style guide are subject of iterative refinement and discussions with project partners. The abovementioned basic elements of interaction are only the basis for the content extension of the style guide with typical user interfaces from network control rooms such as topological or geographical networks. A consolidated version will serve as a basis for user interface design.

Two sides of the same coin - Software Engineering and Human-Centered Design of future energy control room systems

Human-centered design activities like described in the previous sections have to be part of an overall software and usability engineering process leading to open and modular energy management systems with consistent user interfaces. In more detail: 
- Contexts of use (e.g. tasks, workflows, characteristics of workstations) have to be analysed before design solutions are produced. Otherwise, workflows (e.g. low-voltage grid management) will evolve from technical conditions only.

- A style guide from basic elements like typography or colour coding to complex charts and network plans needs to be considered from the beginning. It is not about making design elements "look and feel nice" afterwards.

- Users and stakeholders have to be involved in formative and summative evaluations in order to refine workflows and assess prototypes (see Fig. 11) before implementing them within complex system architectures (e.g. oK multilayer architecture, see Fig. 3).

Last but not least, smart energy systems and low-voltage grid management introduce major challenges (e.g. big data management, security of distributed networks) which have to be regarded from a socio-technical point of view. For example, big data is not only a question of data storage and processing but one of operators' trust and responsibility.

\section{Conclusion}

Usability of smart energy control room systems is of utmost importance for safe and reliable future energy grid management. In addition to their current workload, control room operators will have to deal with further challenges introduced by renewable energies and smart energy systems. With respect to low-voltage grid management, we found a disparity of opinions whether it will affect control room operators' daily routine.

From the results of the research it can be deduced, that many common points exist between control rooms of different fields. Open and modular systems will help to solve mutual problems, but only when applied in conjunction with strict design rules, which can be formulated using a style guide.

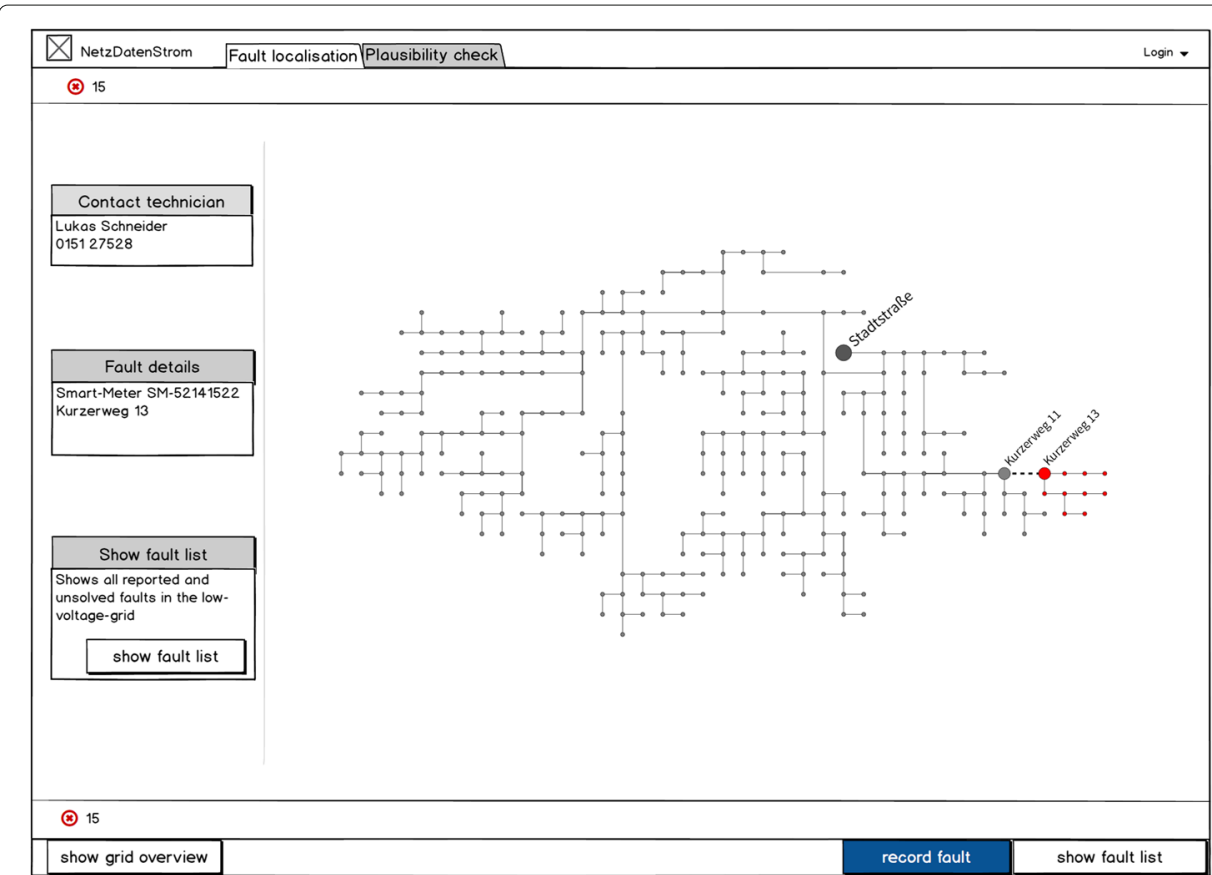

Fig. 11 Low-fidelity prototype regarding low-voltage failure management (image: copyright IMIS) 
Because tools and tasks (have to) co-evolve software engineering and humancentered design should be regarded as two sides of the same coin. Current energy control room systems need to be improved with respect to usability and everything on top needs to be integrated in a careful manner. Special attention must be paid to the fact that design of control rooms varies in terms of number and layout of workstations, human and technical resources as well as operators' responsibilities. Open and modular software systems can be regarded as a technical approach to handle this variety of operating conditions but only if consistent user interface are provided. Therefore, a dynamic, web-based style guide is under development. It will be further used and evaluated within the interdisciplinary research project NetzDatenStrom.

\section{Endnotes}

${ }^{1}$ https://www.bmwi.de/Redaktion/EN/Artikel/Energy/research-for-an-ecologicalreliable-and-affordable-power-supply.html

${ }^{2}$ https://www.openkonsequenz.de/

${ }^{3} \mathrm{http}$ //people.f3.htw-berlin.de/Professoren/Pruemper/instrumente/ISONORM \%209241-110-S.pdf

\section{Abbreviations}

GIS: Geographic information systems; HMI: Human machine interface; IMIS: Institute for Multimedia and Interactive Systems, University of Luebeck; oK: OpenKONSEQUENZ; WIMP: Windows, Icons, Menus, Pointer

\section{Funding}

The authors acknowledge the financial support by the German Federal Ministry of Economic Affairs and Energy in the project NetzDatenStrom (project number 03ET7564B). Publication costs for this article were sponsored by the Smart Energy Showcases - Digital Agenda for the Energy Transition (SINTEG) programme.

\section{Availability of data and materials}

The datasets generated and/or analysed during the current study are not publicly available due to the ongoing nature of the research project but are available from the corresponding author on reasonable request.

\section{About this Supplement}

This article has been published as part of Energy Informatics Volume 1 Supplement 1, 2018: Proceedings of the 7th $\mathrm{DACH}+$ Conference on Energy Informatics. The full contents of the supplement are available online at https:// energyinformatics.springeropen.com/articles/supplements/volume-1-supplement-1.

\footnotetext{
Authors' contributions

MM, TR and TM conducted the contextual inquiry. All authors contributed to the publication and have read and approved the final manuscript.
}

\section{Competing interests}

The authors have no competing interests.

\section{Publisher's Note}

Springer Nature remains neutral with regard to jurisdictional claims in published maps and institutional affiliations.

Published: 10 October 2018

\section{References}

Baumert A (1998) Gestaltungsrichtlinien : Style guides planen, erstellen und pflegen. Doculine Verlags-GmbH, Hannover Beyer H, Holtzblatt K (1998) Contextual design : defining customer-centered systems. In: Morgan Kaufmann, San Diego

Bockelmann M, Nachreiner F, Nickel P (2012) Bildschirmarbeit in Leitwarten Handlungshilfen zur ergonomischen Gestaltung von Arbeitsplätzen nach der Bildschirmarbeitsverordnung. Gesellschaft für Arbeits-, Wirtschafts- und Organisationspsychologische Forschung (GAWO), Dortmund, Berlin, Dresden

Bundesanstalt für Arbeitsschutz und Arbeitsmedizin (BAUA) (2014) Bildschirmarbeit in Leitwarten ergonomisch gestalten. baua Bundesanst. fur Arbeitsschutz und Arbeitsmedizin, Berlin

Butler KA (1996) Usability engineering turns 10. Interactions 3(1):58-75

Carroll JM, Kellogg WA, Rosson MB (1991) Designing interaction : psychology at the human-computer interface. Cambridge University Press, Cambridge

Crampin T (2017) Human Factors in Control Room Design. Wiley, Chichester 
Domova V, Ralph M, Vartiainen E, Muñoz AA, Henriksson A, Timsjo S (2017) Re-Introducing Physical User Interfaces into Industrial Control Rooms. In: Proceedings of the European Conference on Cognitive Ergonomics 2017 - ECCE 2017. ACM Press, New York. pp 162-168

EPRI and U S Department of Energy (2004) Human Factors Guidance for Control Room and Digital Human-System Interface Design and Modification: Guidelines for Planning, Specification, Design, Licensing, Implementation, Training, Operation, and Maintenance. EPRI and U.S Department of Energy, Palo Alto and Washington, DC

Frost B (2016) Atomic design. Brad Frost Web, Pittsburg

Gale S, Stephen (1996) A collaborative approach to developing style guides. In: Proceedings of the SIGCHI conference on Human factors in computing systems common ground - CHI ' 96 . ACM Press, New York. pp 362-367

Goering A, Meister J, Lehnhoff S, Herdt P, Jung M, Rohr M (2017) Reference architecture for open, maintainable and secure software for the operation of energy networks. CIRED Open Access Proc J 2017(1):1410-1413

Goering A, Meister J, Lehnhoff S, Jung M, Rohr M, Herdt P (2016) Architecture and Quality Standards for the Joint Development of Modular Open Source Software for Power Grid Distribution Management Systems. In: D-A-CH+ Energy Informatics 2016

Herczeg M (2014) Prozessführungssysteme : sicherheitskritische Mensch-Maschine-Systeme und interaktive Medien zur Überwachung und Steuerung von Prozessen in Echtzeit. München, De Gruyter Oldenbourg

Herczeg M, Kammler M, Roenspieß A, Mentler T (2013) The Usability Engineering Repository UsER for the Development of Task- and Event-based Human-Machine-Interfaces. IFAC Proc Vol 46(15):483-490

Hollnagel E, Woods DD (2005) Joint cognitive systems : foundations of cognitive systems engineering. Taylor \& Francis, Boca Raton

ISO/TC 159/SC 4 Ergonomics of human-system interaction (2010) ISO 9241-210:2010 Ergonomics of human-system interaction - Part 210: Humancentred design for interactive systems, Vol. 1. International Organization for Standardization

ISO/TC 159/SC 4 Ergonomics of human-system interaction (2013) ISO 11064-4:2013 Ergonomic design of control centres - Part 4: Layout and dimensions of workstations, Vol. 2. International Organization for Standardization

ISO/TC 159/SC 4 Ergonomics of human-system interaction (2018) ISO 9241-11:2018 Ergonomics of human-system interaction - Part 11: Usability: Definitions and concepts, Vol. 2. International Organization for Standardization

Ivergard T (2009) Hunt B. Handbook of control room design and ergonomics : a perspective for the future 2 nd ed. 2nd ed. CRC Press, Boca Raton

Mayhew DJ (1999) The usability engineering lifecycle : a practitioner's handbook for user interface design. Morgan Kaufmann Publishers, West Tisbury

Mentler T (2018) Usability Engineering und User Experience Design sicherheitskritischer Systeme. In: Sicherheitskritische Mensch-Computer-Interaktion. Springer Fachmedien Wiesbaden, Wiesbaden. pp 41-60

Mentler T, Berndt H, Wessel D, Herczeg M (2017) Usability Evaluation of Information Technology in Disaster and Emergency Management. In: Murayama Y, Velev D, Zlateva P, Gonzales JJ (eds). Information Technology in Disaster Risk Reduction First IFIP TC 5 DCITDRR International Conference, ITDRR 2016, Sofia, Bulgaria, November 16-18, 2016, Revised Selected Papers. Springer. Springer, Sofia. pp 46-60

Neureiter C, Eibl G, Engel D, Schlegel S, Uslar M (2016) A concept for engineering smart grid security requirements based on SGAM models. Comput Sci Res Dev 31(1-2):65-71

Pataki K, Sachse K, Prümper J, Thưring M (2006) ISONORM 9241/10-S: Kurzfragebogen zur Software-Evaluation. In: Berichte ùber den 45. Kongress der Deutschen Gesellschaft für Psychologie. Pabst Science Publishers, Lengerich. pp 258-259

Preim B, Dachselt R (2015) Styleguides im User Interface Engineering. Springer Vieweg, Berlin, Heidelberg

Rae A (2007) Helping the Operator in the Loop : Practical Human Machine Interface Principles for Safe Computer Controlled Systems Vol. 86. pp 61-70. https://pdfs.semanticscholar.org/6700/d4f9e7d1157b3c9394b655e44abd296244dc.pdf

Reed P, Holdaway K, Isensee S, Buie E, Fox J, Williams J, et al. (1999) User interface guidelines and standards: progress, issues, and prospects. Interact Comput 12(2):119-142

Roenspieß A, Herczeg M (2013) Interaktive und rollenspezifische Styleguides im Usability-Engineering. In: Boll S, Maaß S, Malaka R (eds). Mensch \& Computer 2013: Interaktive Vielfalt. Oldenbourg Verlag, München. pp 285-288

Rosson M, Beth C, Millar J (2002) Usability engineering : scenario-based development of human-computer interaction. Academic Press, San Francisco

Santini S, Tiefenbeck V (2018) 6th DACH+ Conference on Energy informatics (EnInf 2017). Comput Sci Res Dev 33(1-2):1-2

Savioja P, Aaltonen I, Karvonen H, Koskinen H, Laarni J, Liinasuo M, et al. (2012) Systems Usability Concerns in Hybrid Control Rooms. In: Proceedings of the 8th International Topical Meeting on Nuclear Plant Instrumentation and Control and Human-Machine Interface Technologies. American Nuclear Society, San Diego

Savioja P, Liinasuo M, Koskinen H (2014) User experience: does it matter in complex systems?. Cogn Technol Work 16(4):429-449

Schwarz T (2015) Holistic Workspace - Gestaltung von realitätsbasierten Interaktions- und Visualisierungskonzepten im Kontext von Leitwarten. Konstanz, Universität Konstanz

Shepherd A (1998) HTA as a framework for task analysis. Ergonomics 41(11):1537-1552

Wang J, Qi C (2012) The Design of Control System for Smart Meter. In: 2012 International Conference on Computer Science and Service System. IEEE, Nanjing. pp 1961-1964

Wilson CE (2001) Guidance on Style Guides: Lessons Learned. In: Usability Interface, no. 4. Vol. 7. pp 1-7. https://immagic. com/eLibrary/ARCHIVES/GENERAL/GENPRESS/S010400W.pdf 